\title{
Do Task Complexity Demands Influence the Learners' Perception of Task Difficulty?
}

\author{
Nasrin Sanajou (Corresponding author) \\ University of Mohaghegh Ardebili, Iran \\ E-mail: n.sanajoo@yahoo.com \\ Leila Zohali \\ Shiraz University of Medical Science, Iran \\ E-mail: Lzohali69@gmail.com \\ Fateme Zabihi \\ University of Bojnourd, Iran \\ E-mail: Fateme.zabihi@yahoo.com
}

Received: 12-04-2017

Published: 01-11-2017
Accepted: 25-05-2017

doi:10.7575/aiac.ijalel.v.6n.6p.71
Advance Access Published: September 2017

URL: http://dx.doi.org/10.7575/aiac.ijalel.v.6n.6p.71

\begin{abstract}
This study investigates the effects of cognitive task complexity on EFL learners' perception of task difficulty. Learners' perception of task difficulty is measured by a five-item task difficulty questionnaire (as in Robinson, 2001a). The participants were 76 intermediate learners which were divided into two groups. One group performed a simple task (single task) and the other group performed a complex task (dual task). Having performed the tasks, the participants completed the task difficulty questionnaire. In order to see how the participants evaluated task difficulty, their ratings for each question of the questionnaire in the simple and complex tasks was compared using Mann-Whitney U. The results indicate that the complex task significantly affected learners' perception of task difficulty in three items of difficulty, stress and interest. The results of task difficulty studies can help language educators in designing and employing more effective language teaching materials.
\end{abstract}

Keywords: Task complexity, Task difficulty, Single task, Dual task

\section{Introduction}

For the past 20 years, task-based language teaching (TBLT) has attracted attention of second language acquisition (SLA) researchers (Branden, 2006). Having used tasks as the basic unit of language courses, a key discussion is on what criteria tasks should be sequenced and ordered. Cognitive approach is one of the suggested criteria for designing and sequencing tasks. From information processing perspective to TBLT, cognitive complexity of the task is a very important feature (Robinson, 2001) which has been concerned with psychological processes learners are engaged in while doing tasks (Skehan, 2003). Task Complexity (Skehan, 1998) also deals with the impact of manipulating cognitive task complexity on learners' performance. There are two contrasting views in cognitive approach to task: 1) Skehan's (1998) Limited Attentional Capacity Model (LAC) and 2) Robinson's Cognition Hypothesis (CH). Skehan (1998) proposes that attentional resources are limited, and that to attend to one of the aspects of performance complexity, accuracy, or fluency of language may suffer the other dimensions. For example, much attention being paid to fluency will increase it; however, other dimensions (accuracy and complexity) might decrease this way. In contrast, Robinson (2001) believes that attentional resources are not limited and learners can access multiple and non-competing attentional resources. He also states that complexity and accuracy in a task are correlated since they are each driven by the nature of functional linguistic demands of the task itself. He says that fluency is in contrast with complexity and accuracy, which correlate with one another. Following Robinson's cognition hypothesis which claims that tasks should be designed and sequenced on the basis of an increase in their cognitive complexity (Robinson, 2001a), a number of studies have investigated the effects of task complexity, task difficulty, task design, and performance conditions on learners' performance (Skehan \& Foster, 1999; Ellis, 2004; Kuiken \& Vedder, 2007, 2008). Although so many studies have investigated task complexity and performance conditions, there have been no more than a handful of studies investigating learners' perception of task difficulty (Robinson, 2001, 2007; Gilabert, 2007). Therefore, the present study explores the relationship between task complexity and learners' ratings of task difficulty. 


\subsection{Task difficulty}

Following the use of cognitive task complexity as a criterion for sequencing tasks, several proposals have been made on task classification (i.e., Brown et al.,'s 1984 classification; Skehan's 1998 model; Robinson's triadic componential framework, 2001, 2005, \& 2007). In the earliest classification of task difficulty, Brown, Anderson, Shilcock, and Yule (1984) suggest to sequence tasks from simple to complex. They distinguish among three different types of tasks. In the first type, which is known as static task and is the easiest one, all the information to be exchanged is presented to the speaker in the input and the information does not change during the course of the activity (e.g., a map task in which the speaker has to give directions to the listener). In the second type, dynamic task, like the first type, the speaker is given all the information in stimulus materials, except that the elements (characters, events, and activities) change while the task is being performed (e.g., a story in a comic strip in which characters appear and disappear or change places and behaviors). In the last and the most difficult type, abstract task, they are given decontextualized elements (the input does not contain the content to be communicated). Abstract tasks require manipulating, making reference to abstract concepts, establishing connections between ideas, and providing reasons for certain statements or behaviors (e.g., expressing opinions).

In another classification, Skehan (1998) proposes three factors of code complexity including "language required" (Skehan, 1998, p. 99), cognitive complexity "thinking required" (p. 99), and communicative stress "performance condition" (p. 99) for a task. Code complexity has to do with two areas of syntactic and lexical difficulty of the tasks (Skehan, 1996). Cognitive complexity is concerned with content features of input. He makes a distinction between two aspects of cognition namely: cognitive familiarity and cognitive processing. Cognitive familiarity refers to the "access to ready-made or pre-packaged solutions" (Skehan, 1996, p. 52). Cognitive processing, in contrast, refers to the "work out solutions to novel problems" (p. 99). In other words, task completion requires on-line computations and active thinking (Skehan, 1996). The third factor, communicative stress, is concerned with conditions under which the task needs to be done. Aspects involved in communicative stress are: (1) time limits and time pressure; (2) speed of presentation; (3) number of the participants; (4) length of texts used; (5) type of response (modality); (6) opportunity to control interaction (the influence that participants can have on task in the way that it is done).

Yet, in another task classification, Robinson (2001, 2005, \& 2007) proposes the triadic componential framework (TCF) for sequencing tasks. In this framework, he distinguishes three dimensions of task complexity, task conditions and task difficulty. These dimensions of complexity are design features of tasks which can be manipulated to increase or lessen the cognitive demands which tasks make on the learners while they are performing the task. Task complexity refers to "the intrinsic cognitive demands of the task" (Robinson, 2003, p. 55). Task complexity consists of two types of the resource-directing variables which "make greater resource demand, but lead learners to use specific features of the language code" (Robinson, 2005, p. 4) and the resource-dispersing variables which "make greater resource demand without leading them to use specific features of language code" (Robinson, 2001, p. 31). Task condition is the feature of tasks which are determined by the situational setting, and conditions in which they take place. This category includes two components of participation variables (i.e. open/close tasks, one way/ two way tasks) and participant variables (i.e. same or different gender, extent of familiarity). Task difficulty is "between learners variables" (Robinson, 2001, p. 32) and is concerned with the learners' perception of the demands made by the task and the resources learners bring to the task. Task difficulty in turn consists of two variables: (1) affective variables (i.e. motivation, anxiety) and ability variables (i.e. intelligence, working memory).

The present study is an attempt to see how the learners evaluate task difficulty along cognitive task complexity which is manipulated by single and dual tasks. Learners' perception of task difficulty is measured by a five-item task difficulty questionnaire (as in Robinson, 2001a) which includes items of difficulty, stress, confidence, interest, and motivation.

Research Question: Is there any significant difference in the learners' perception of task difficulty in single vs. dual tasks?

\section{Literature Review}

Understanding learners' perception of task difficulty (TD) will assist task designers in designing and employing more effective language teaching materials. Unfortunately, very little has been done on learner's perception of task difficulty which are Nunan and Keobke (1995), Robinson (2001a), and Tavakoli and Skehan (2005). Nunan and Keobke (1995) are among the first scholars investigating learner's perception of TD. The participants who were 35 undergraduate Cantonese-speaking students performed some reading, listening and speaking tasks and were asked to report their perception of the degree of the task difficulty and the reason of the difficulty of the task. The most important factors identified by learners were lack of familiarity with task types, confusion over task purpose, and the impact and extent of cultural knowledge.

Robinson (2001a) examined the effects of the cognitive complexity of tasks on the language production and learners' perception of task difficulty. He used a speaking task in which participants performed two versions of the directiongiving map task. In both tasks, the participants were asked to give a direction from point A to point B on a map. The difference between simple and complex version was that in the former the map covered a small and familiar area, while in the latter the map covered a large and familiar area. In other words, task complexity was manipulated along the amount of information and availability of prior knowledge. Learners' perception of task difficulty was measured by a five-item task difficulty questionnaire including difficulty, stress, confidence, interest, and motivation. He concluded that cognitive complexity significantly affected learners' perception of difficulty in terms of stress and difficulty. 
In a study, Tavakoli and Skehan (2005) examined the influence of the structure of oral narrative tasks on learners' perception of TD. The learners were asked to perform four narrative tasks and then a retrospective questionnaire was used to determine which task was the most difficult one. The results indicated that task structure affected learners' perception of TD, in a way that the more structured tasks were rated by learners as easier than the less structured tasks. In another study, Tavakoli (2009) investigated learners and teachers' perception of task difficulty. The learners and teachers were given four oral narrative tasks and during a retrospective interview they were asked to identify the most difficult tasks and the factors that contributed to the difficulty of those tasks. She concluded that several variables such as cognitive and linguistic demand, the amount of information needed to complete a task, and task structure influenced the learners and teachers' perception of TD.

\section{Method}

This study explores the relationship between task complexity and participants' perception of task difficulty. The research question is "Is there any significant difference in the learners' perception of task difficulty in single vs. dual tasks?" The null hypothesis is "There is not any significant difference in the learners' perception of task difficulty in single vs. dual tasks."

\subsection{Participants}

The participants of this study were 76 Iranian BA students at the intermediate level. They were majoring in teaching English as a foreign language (TEFL) in Mohaghegh University in Ardebil, one of the cities in Iran. They were all between 18 and 29 years old, and were both female and male. Moreover, they were randomly selected from a pool of 118 language learners who were freshmen and sophomores.

\subsection{Instruments}

Four major instruments were used in this study. The first one was the writing section of the free sample PET (2015) which was used as a pretest and proficiency test. At the beginning of the study to ensure the homogeneity of the participants in terms of writing proficiency, just the writing section of the sample PET was administered. The second and the third instruments were the single and dual tasks. These tasks were narrative tasks which consisted of eight pictures and were comic strip (Jahanshahi 1978). In the single task (Appendix A), participants were asked to write the story of the comic strip (at least 100 words) in 15 minutes. In the dual task (Appendix B) pictures of the comic strip were disordered. So, the participants were asked to first think and find the correct sequence of pictures and then write the story (at least in 100 words) in 25 minutes (the time limits for performing both the single and dual tasks were selected based on the pilot study). The only difference between the single task and the dual one was that the latter was [+ dual task], i.e. the participants had to both think of the correct sequence, and write a story about it as well (Robinson, 2007). The fourth instrument was difficulty questionnaire (as in Robinson, 2001, Appendix C) which was used to measure learners' perception of task difficulty. The task difficulty questionnaire had five questions. The participants were asked to rate on a nine point scale for each question. The questions were about the difficulty (whether they thought the task was difficult), stress (whether they felt stress performing the task), ability (whether they felt confident that they were able to do the task well), interest (whether they thought the task was interesting), and motivation (whether they wanted to do more tasks like the one they did).

\subsection{Procedure}

At the beginning of the study, four intact classes including 118 participants who were in their first and second year sat for the writing section of a sample PET (2015). Using Jacobs et al.'s (1981, cited in Weigle, 2002) Scoring Profile, two experienced raters scored the writing production of the participants. Each participant's final score was calculated by averaging the given scores by the two raters. The inter-rater reliability of scores was checked using Pearson-product moment correlation coefficient. The results indicated relatively high inter-rater reliability.

Having checked reliability, normality of the distribution of the data was checked via skewedness and kurtosis, the one sample Kolmogorov Smirnov and the box plot. Then, the descriptive statistics were run to determine the writing proficiency level of participants. Finally, 76 students at the intermediate level whose score were one SD above and below the mean were selected as the participants of the study. To conduct the main study, two out of the four classes were randomly assigned to perform the single task and the other two classes performed the dual task. Right after performing the tasks, the participants were given the task difficulty questionnaire and were asked to complete. After the data was collected, five Mann-Whitney U were conducted to compare participants' ratings on each of the questions of the questionnaire.

\subsection{Design}

This study is a quantitative, between-groups design (Hatch \& Lazaraton, 1991). There is one independent variable, cognitive task complexity, with two levels i.e., single vs. dual tasks and one dependent variable (task difficulty) with five levels i.e., difficulty, stress, confidence, interest, and motivation (which are investigated independently of each other).

\section{Results}

In order to see if the participants' ratings of the questionnaire are different in the two groups or not, descriptive statistics were run (Table 1). By comparing the mean scores of the first question of the questionnaire, difficulty question, it is obvious that the mean score of the dual task $(X=3.68)$ is higher than the mean score of the single task $(X=1.95)$. This means that the participants rated the dual task more difficult than the single task. A Mann-Whitney $\mathrm{U}$ was conducted for 
checking the meaningfulness of the difference between the two mean scores. The results of Mann-Whitney $\mathrm{U}(t=-4.25$; $p<0.05)$ indicate that the difference between the mean scores is meaningful and statistically significant.

Table 1. Descriptive Statistics of the Participants' Ratings to the Task Difficulty Questionnaire

\begin{tabular}{llllcc}
\hline & & $\mathrm{N}$ & Mean & Std. Deviation & Std. Error of mean \\
\hline Single task & difficulty & 38 & 1.95 & 1.18 & 0.19 \\
& stress & 38 & 1.53 & 0.86 & 0.14 \\
& ability & 38 & 5.95 & 2.56 & 0.41 \\
& interest & 38 & 5.50 & 2.44 & 0.39 \\
& motivation & 38 & 6.39 & 2.17 & 0.44 \\
\hline Dual task & difficulty & 38 & 3.68 & 1.91 & 0.31 \\
& stress & 38 & 2.34 & 1.64 & 0.26 \\
& ability & 38 & 5.89 & 2.09 & 0.33 \\
& interest & 38 & 4.29 & 2.74 & 0.44 \\
& motivation & 38 & 5.18 & 3.09 & 0.50 \\
\hline
\end{tabular}

The mean scores of the second question of the questionnaire, which is about the degree of the stress they felt during performing the task, are different for the two tasks. The mean score of the stress for the dual task $(\mathrm{X}=2.34)$ is higher than the mean score of the single task $(X=1.53)$. In order to determine whether the difference between mean scores are meaningful or not, a Mann-Whitney $\mathrm{U}$ was conducted. Based on the results of the Mann-Whitney $\mathrm{U}(t=-2.39 ; p<$ 0.05 ) the difference between the mean scores of the two groups is meaningful. So, the dual task was rated to be more stressful than the single task. In other words, the dual task is rated significantly more difficult than the single task.

Regarding the third question of the questionnaire, which checks the participants' perception of their ability level, the mean score of the single task $(X=5.95)$ is higher than the mean score of the dual task $(X=5.89)$, which means that participants in the single task felt more confident while doing the task than the participants of the dual task. The results of the Mann-Whitney $\mathrm{U}(t=-0.31 ; p>0.05)$ indicate that the difference between the mean scores is not meaningful. In other words, task complexity does not affect the learners' perception of their ability in doing the single vs. dual tasks. Although the mean score of the single task is higher than the dual task, the difference is not significant.

The fourth question of the questionnaire concerns the participants' interest in doing single vs. dual tasks. The descriptive statistics of the learners' rating to their interest in performing the tasks reveals a higher mean score for the single task $(X=5.50)$ than the dual task $(X=4.29)$. The results of the Mann-Whitney $\mathrm{U}(t=-2.06 ; p<0.05)$ indicates that the difference between the mean scores of the participants' interest is meaningful. In other words, the participants of the single task were more interested in doing the task than the participants of the dual task.

Finally, the fifth question of the questionnaire addresses the difference in the motivation of the participants in performing the single vs. dual tasks. The mean score of the participants' motivation in the single task $(\mathrm{X}=6.39)$ is higher than the mean score of the participants in the dual task $(\mathrm{X}=5.18)$. The results of Mann-Whitney $\mathrm{U}(t=-1.62 ; p$ $>0.05$ ) indicates that the difference between the mean scores is not statistically significant. It means that although the participants in the single task were more motivated in doing the task, the difference was not statistically significant.

\section{Discussion}

This study explores the effect of task complexity demands on EFL learners' perception of the difficulty of narrative tasks. Task difficulty, which deals with the learners' perception of task demands, is likely to influence production and learning opportunities that tasks provide. As the results indicate, different cognitive task complexity degrees had an effect on ratings of the task difficulty. Based on the results, the participants rated the complex task more difficult than the simple task. This finding is completely in line with Robinson (2001a, 2007) and Gilabert (2007) in which they reported that the participants rated the complex task more difficult than the simple one. A possible explanation for rating the dual task (complex task) as the more difficult one maybe that performing two tasks simultaneously puts higher cognitive load on the learners, and makes the task more difficult for them. Instead, low cognitive load of the single task makes the task less difficult, which resulted in less difficulty ratings on the single (simple) task.

Regarding the second question, like Robinson's (2001a, 2007) and Gilabert's (2007) study the results indicated that the complex task was rated to be more stressful than the simple task. In the dual task, participants had to perform two tasks which placed higher processing demands on them. The high cognitive demand of the dual task made the task more stressful for participants. While cognitive load of the single task was not high due to the fact that the participants had to perform one task at a time. As a result of less cognitive load the single task was recognized not to be stressful for the participants.

With regard to the results of the third question, there is no significant difference in the mean scores of the two groups. Although the mean score of the single task is higher than the dual task, the difference is not statistically significant. The non-significant result of the question related to stress supports the result of the Robinson's (2001a) study. But the result 
does not support the findings of Robinson (2007) and Gilabert (2007) in which they found a significant difference in the ratings of stress in the two groups. Given high cognitive demands of the dual task, the ability ratings of the dual task are no more different from the ability ratings of the single task. These unaffected ability ratings can be explained in part by the fact that unlike speaking, in which the participants are under real-time pressure, in the writing task, they do not have to perform under real-time pressure. Therefore, given the opportunity of not being under real-time pressure, they have time to think and do the task, so the dual task participants' confidence in performing the task was not different from single task participants. To restate, we can conclude that the confidence of the participants of the two groups was not affected by task complexity.

Unlike the results of Robison (2001a, 2007) and Gilabert (2007) which did not report a significant difference in the ratings of interest, the results of this study indicated that the participants of the single task were significantly more interested in doing the task than the participants of the dual task. The low interest ratings of the dual task can be related to the fact that doing two tasks puts high cognitive demand on them, which made the task difficult for them. As a result the participants were less interested in performing the dual task. On the other hand, the participants of the single task were asked to perform one task which places less cognitive demand on them, consequently they were more interested in performing the task. Although, the participants of single task rated the task more interesting than the dual task, the mean score of the dual task was not very low. This means that the participants of dual task were not frustrated with the high processing demands of the dual task.

Finally, the findings of the fifth question was completely in line with the results of Robinson (2001a, 2007) and Gilabert (2007). The high mean score of the single task suggests that the participants of this task were much motivated in doing the task than participants of the dual task. Like ratings of interest, the mean score of motivation in the dual task is not very low, which suggests that increasing the cognitive complexity of tasks does not result in loss of interest and motivation in performing the task. Building on the results, we can conclude that task complexity did not influence the participants' motivation in performing the tasks.

All in all, the results suggest that participants' ratings on difficulty, stress, and interest are higher in the complex task, while ratings of motivation and ability are not significantly influenced. Therefore, the null hypothesis of the study is rejected. Overall, the findings of this study regarding participants' perception of difficulty are in line with Robinson's findings.

\section{Conclusion}

The present study investigates the influence of task complexity, which is manipulated along single vs. dual tasks, on the participants' perception of TD. The results show that ratings of overall difficulty, stress, and interest are significantly higher on the complex task (dual task). While the ratings of ability and motivation do not differ significantly. The findings of this study support the principles of a cognitive model of TD, as the data suggest that the cognitive demands of a task perceived by the learners is a significant factor contributing to TD. These findings imply that L2 teachers and task designers need to consider the cognitive demands of a task while they are choosing and/ or designing L2 teaching tasks. Teachers and task designers should try to find tasks that have an appropriate level of difficulty.

\section{References}

Branden, K. V. (2006). Task-based language education. Cambridge: CUP.

Brown, G., Anderson, A., Shilcock, R., \& Yule, G. (1984). Teaching talk: Strategies for production and assessment. Cambridge: CUP.

Ellis, R., \& Yuan, F. (2004). The effects of planning on fluency, complexity, and accuracy in secong language narrative writing. SSLA, 26, 59-84. doi: 10.1017/S0272263104261034

Gilabert, R. (2007). The simultaneous manipulation of task complexity along planning time and [+/- Here-and-now]: Effects on L2 oral production. In M. del Pilar Garcia-Mayo (Ed.), Investigating tasks in formal language learning (pp. 44-68). Clevedon, Avon: Multilingual Matters.

Hatch \& Lazartan (1991) Hatch, E., \& Lazaraton, A. (1991). The research manual: Design and statistics for applied linguistics. Boston: A devision of wadsworth, Inco.

Jahanshahi, I. (1978). Qessehaye man va babam: Babaye khube man. Tehran: Fatemi Publication.

Kuiken, F., \& Vedder, I. (2007). Task complexity and measures of linguistics performance in L2 writing. International Review of Applied Linguistics in Language Teaching, 45, 261-284. doi: 10.1515/IRAL.2007.012

Kuiken, F., \& Vedder, I. (2008). Cognitive task complexity and written output in Italian and French as a foreign language. Journal of Second Language Writing, 17, 48-60.

Nunan, D., \& Keobke, K. (1995) Task difficulty from the learner's perspective: perceptions and reality. Hong Kong Papers in Linguistics and Language Teaching 18: 1-12.

Robinson, P. (2001a). Task complexit, task difficulty, and task production: exploring interactions in a componential framework. Applied Linguistics, 22(1), 27-57.

Robinson, P. (2003). The cognition hypothesis, task design, and adult task-based language learning. Second Language Studies, 21(2), 45-105. 
Robinson, P. (2005). Cognitive complexity and task sequencing: A review of studies in a Componential Framework for second language task design. International Review of Applied Linguistics in Language Teaching, 43(1), 1-33.

Robinson, P. (2007).Task complexity, theory of mind, and intentional reasoning: Effects on L2 speech production, interaction, uptake and perceptions of task difficulty. IRAL, 45, 193-213. doi:10.1515/IRAL.2007.009

Skehan, P. (1996). A framework for the implementation of task-based instruction. Applied Linguistics, 17(1), 38-62.

Skehan, P. (1998). A cognitive approach to language learning. Oxford: Oxford University Press.

Skehan, P., \& Foster, P. (1999). The influence of task structure and processing conditions on narrative retellings. Language Learning, 49(1), 93-120.

Skehan, P. (2003). Task-based instruction. Language Teaching, 36, 1-14.

Tavakoli, P., \& Skehan, P. (2005) Strategic planning, task structure and performance testing. In R. Ellis (ed.), Planning and task performance in a second language. Amsterdam: Benjamins. 239-77.

Tavakoli, P. (2009). Investigating task difficulty: learners' and teachers' perceptions. International Journal of Applied Linguistics, 19(1), 1-25.

Weigle, S. C. (2002). Assessing writing. Cambridge: CUP.

\section{Appendices}

Appendix 1 The comic strip of the single task
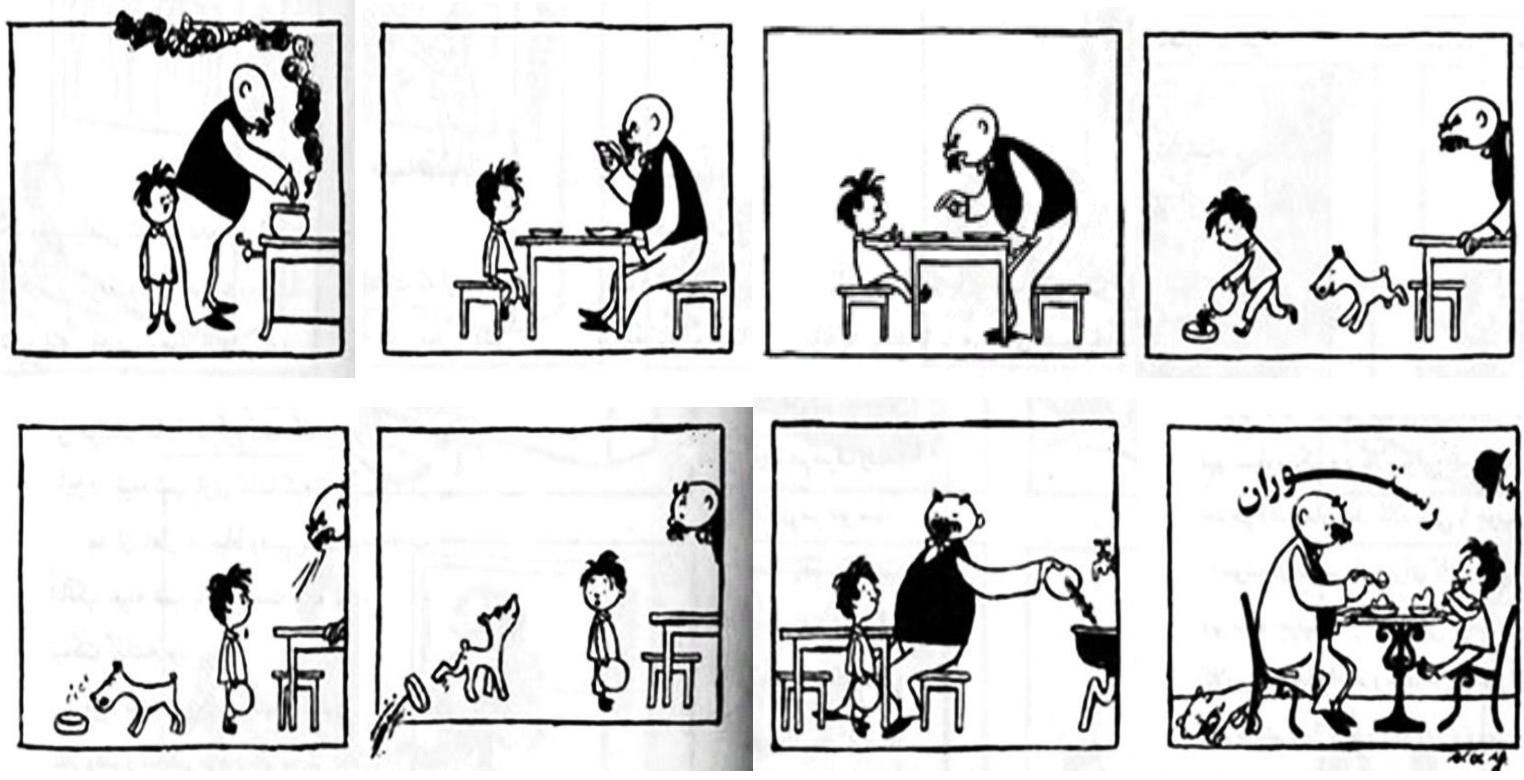

Appendix 2 The comic strip of the dual task
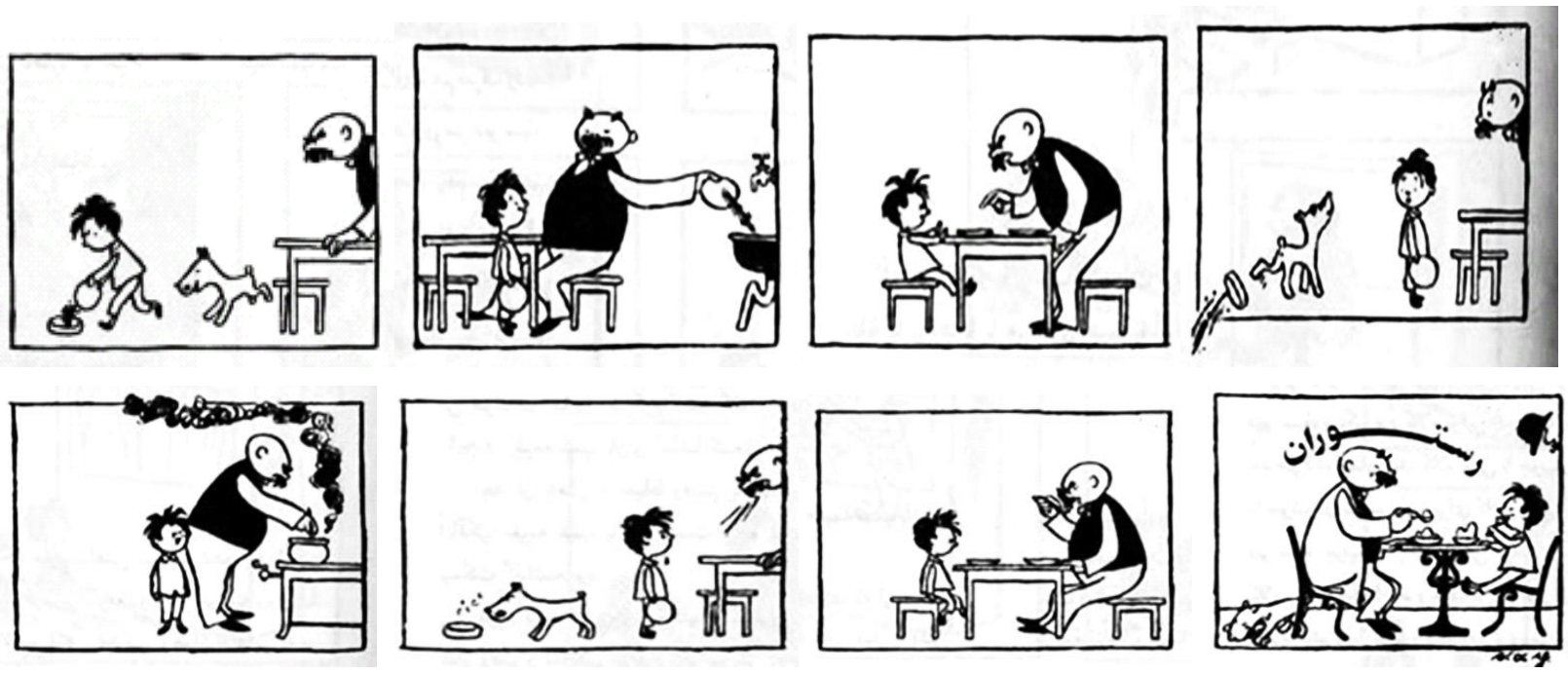


\section{Questionnaire}

Name:

\section{Semester:}

Dear Participant: Read the statements below. Then, indicate your extent of agreement or disagreement by circling one of the numbers from one to nine.

\begin{tabular}{|l|l|c|}
\hline 1 & I thought this task was easy/ I thought this task was hard: & 123456789 \\
\hline 2 & $\begin{array}{l}\text { I felt relaxed doing this task/ I felt frustrated doing this task: } \\
\text { (1. no stress, 9. a lot of stress) }\end{array}$ & 123456789 \\
\hline 3 & $\begin{array}{l}\text { I didn't do well on this task/ I did well on this task: } \\
\text { (1. not confident, 9. very confident) }\end{array}$ & 123456789 \\
\hline 4 & $\begin{array}{l}\text { This task was not interesting/ this task was interesting: } \\
\text { (1 not interesting, 9 very interesting) }\end{array}$ & 123456789 \\
\hline 5 & $\begin{array}{l}\text { I don't want to do more tasks like this/ I want to do more tasks like this: } \\
\text { (1 do not want to, 9 would like to) }\end{array}$ & 123456789 \\
\hline
\end{tabular}

